\title{
AUDIT SISTEM INFORMASI HUMAN RESOURCE INFORMATION SYSTEM (HRIS) PADA BAGIAN HUMAN RESOURCE (HR) MENGGUNAKAN FRAMEWORK COBIT 5 DOMAIN DSS01
}

\author{
Sri Kurniasih $^{* 1}$, Siti Masitoh ${ }^{2}$ \\ STMIK LPKIA BANDUNG \\ Email : ${ }^{1}$ sri.kurniasih@yahoo.co.id, ${ }^{2}$ masitohsiti664@gmail.com
}

\begin{abstract}
Abstrak
PT Sansan Saudartex Jaya merupakan perusahaan yang bergerak di bidang usaha manufaktur. Kebutuhan tenaga kerja yang terus meningkat dan kegiatan ketenagakerjaan yang perlu terintegrasi antar cabang, memerlukan sebuah koordinasi melalui sebuah sistem Sistem Informasi Human Resource Information System (HRIS). Untuk mengetahui tingkat pengelolaan proses Sistem Informasi HRIS pada bagian HR. dengan kebutuhan saat ini diperlukan pengukuran tingkat kapabilitas proses. COBIT 5 merupakan kerangka kerja yang digunakan untuk mengukur tingkat kapabilitas proses sistem informasi membantu pengumpulan data audit. Langkah penelitian ini dimulai dari tahap studi kepustakaan dengan menelaah dokumen bisnis dan studi literatur materi penelitian, kemudian melakukan wawancara, observasi dan kuesioner pada tahap pengumpulan data dan melakukan pengelolaan data. Dari hasil tersebut dilakukan proses penilaian tingkat kapabilitas dan analisa kesenjangan (gap analysis), sebelum akhirnya hasil audit akan diverifikasi dan melewati tahap strategi perbaikan dan tahap rekomendasi proses. Melalui hasil pengukuran tingkat kapabilitas proses 1 (performed process) dan tingkat 2 (managed process). sehingga berdasarkan analisis gap secara garis besar perlu adanya peningkatan target yang dilakukan dari kondisi saat ini dengan memaksimalkan proses yang sudah berjalan dengan baik serta melakukan inovasi untuk mencapai kondisi yang diharapkan.

Penelitian ini difokuskan pada penggunaan Deliver, Service dan Support (DSS) pada sub domain DSSO1, dengan dilakukannya audit ini diharapkan dapat diketahui tingkat keamanan asset, pemeliharaan integritas data serta dapat mendorong pencapaian tujuan perusahaan secara efektif, menggunakan sumber daya secara effisien dan dapat mengetahui tingkat kematangan teknologi informasi di PT. Sansan Saudaratex Jaya Garment serta menghasilkan rekomendasi untuk mencapai tingkat kematangan sistem informasi yang optimal sehingga dapat membantu merealisasikan visi, misi, dan tujuan PT. Sansan Saudaratex Jaya Garment.
\end{abstract}

Kata Kunci : Audit Sistem Informasi, Sistem Informasi Human Resource Information System ,COBIT 5, Domain DSS

\begin{abstract}
Sansan Saudaratext Jaya Ltd. is a manufacture company that needs integrated system to accommodate the improvement of both employee recruitment and intra-branch employment activities. Therefore, the implementation of Human Resource Information System (HRIS) is considered appropriate to detect the level of capability measurement process. COBIT 5 is a framework which is used to measure the process of capability level in informational system so it can help gaining audit data. This study is started by doing literary review of business document, and research material. The next step is interviewing, observing, and giving questionnaire in data collection and analysis. After gaining the result of data analysis, the step is continued by grading process of capability level and analyzing the gap before it is closed by auditing and verifying through revision and recommendation stages. The processes are in two level: the result of
\end{abstract}


capability measurement level process 1 (performed process) and capability measurement level process 2 (managed process). Based on the result of gap analysis, it can be concluded that there is a need of target improvement of current condition by maximizing the running process and a need of innovation to reach the expected condition.

This study focuses on the use of Deliver, Service dan Support (DSS) at sub domain. By conducting this audit, it is expected to know the level of asset security, data integrity maintenance and it can support the company achievement effectively, use resources efficiently, and detect the level of IT understanding at Sansan Saudaratex Jaya Garment Ltd, and produce recommendation to reach the maturity level of information system optimally. Therefore, at end it can help realizing vision, mission and purpose of Sansan Saudaratex Jaya Garment Ltd.

Keywords : audit of Information System, information system, Human Resource Information System ,COBIT 5, Domain DSS

\section{PENDAHULUAN}

\subsection{Latar Belakang}

Audit dan analisis sistem informasi merupakan cara untuk melakukan pemeriksaan dan menilai serta mengukur sejauh mana sistem informasi dapat menjawab kebutuhan dalam proses bisnis di perusahaan. PT Sansan Saudartex merupakan perusahaan manufaktur dalam menjalankan proses bisnis pada bidang manufaktur, dituntut untuk dapat memaksimalkan seluruh sumber daya yang ada di perusahaan sehingga dapat mencapai tujuan bisnis perusahaan yaitu untuk memperoleh laba semaksimal mungkin. Proses produksi PT. Sansan Saudaratex Jaya Garment termasuk ke dalam proses terus menerus atau continous product, karena perusahaan tersebut akan tetap beroperasi setiap harinya, tanpa menunggu pesanan terlebih dahulu. Untuk itu perlu dilakukan evaluasi pada sistem informasi yang dimiliki oleh perusahaan ini, salah satunya adalah pada bagian Human
Resource. Belum pernah dilakukannya evaluasi pada fungsi sistem informasi Informasi Human Resource Information System (HRIS) pada bagian sumber daya manusia ini, apakah sudah sejalan dengan proses bisnis dan tujuannya, sehingga apabila ada masalah bisa dijadikan tolak ukur untuk melakukan perubahaan di kemudian hari. Pemanfaatan sistem ini diharapkan dapat mempermudah kegiatan operasional yang dilakukan dan membantu pencapaian strategi perusahaan terhadap visi, misi dan tujuan perusahaan. Suatu sistem dikatakan baik adalah sistem yang sesuai dengan prosedur yang telah ditetapkan perusahaan, membantu dalam pencapaian tujuan perusahaan secara efektif dan efisien.

Peneliti melakukan evaluasi pada salah satu teknologi informasi yang di miliki PT.Sansan Saudaratex Jaya dengan menggunakan kerangka kerja COBIT 5. Menurut ISACA 2013, COBIT 5 berperan dalam membantu untuk menyelaraskan antara penggunaan sumber daya, 
penggunaan teknologi informasi, hingga dalam pengelolaan resiko. Salah satu metode evaluasi tata kelola TI adalah Control Objective and related Technologi (COBIT), Juga dirancang sebagai alat bantu dalam memecahkan permasalahan pada IT Governance dalam memahami, mengelola dan mengoptimalkan serta keuntungan yang berhubungan dengan sumber daya informasi organisasi. (ISACA, 2012) [7]

Penelitian ini, difokuskan pada penggunaan Deliver, Service dan Support (DSS) pada sub domain DSS01, dengan dilakukannya audit ini diharapkan dapat diketahui tingkat keamanan asset, pemeliharaan integritas data serta dapat mendorong pencapaian tujuan perusahaan secara efektif, menggunakan sumberdaya secara effisien dan dapat mengetahui tingkat kematangan teknologi informasi serta menghasilkan rekomendasi untuk mencapai tingkat kematangan yang optimal sehingga dapat membantu merealisasikan visi, misi, dan tujuan PT. Sansan Saudaratex Jaya Garment.

\subsection{Identifikasi Masalah}

1. Bagaimana capability level dari hasil Audit Sistem Informasi yang dilakukan di PT. Sansan Saudaratex Java tertama pada Sistem informasi Human Resource Information System (HRIS) pada bagian HR dengan menggunakan COBIT 5 domain DSS01.
2. Apakah sistem informasi Informasi yang saat ini telah berjalan dan mendukung tujuan bisnis perusahaan?.

\subsection{Ruang Lingkup Permasalahan}

Untuk ruang lingkup permasalahan yang ada dalam penelitian ini, dibatasi pada :

1. Sistem informasi Human Resource Information System (HRIS0) pada bagian HR di PT. Sansan Saudaratex Jaya

2. Tidak membuat master plan aplikasi dan road map.

3. Proses bisnis yang diteliti hanya pada bagian yang berkaitan dengan domain DSS01 yaitu Mengelola Operasi.

\subsection{Tujuan Perancangan}

Adapun tujuan dari penelitian ini adalah :

1. Untuk mengetahui hasil pencapaian capability level pada Sistem informasi Human Resource Information System (HRIS0) pada bagian HR di PT. Sansan Saudaratex Jaya.

2. Untuk mengetahui sistem informasi Informasi Human Resource Information System (HRIS) yang saat ini agar dapat mendukung tujuan bisnis perusahaan.

\section{Tinjauan Pustaka}

\subsection{Audit Sistem Informasi}

Menurut Ron Weber "Audit Sistem Informasi yaitu proses mengumpulkan dan mengevaluasi 
fakta untuk memutuskan apakah sistem komputer yang merupakan aset perusahaan terlindungi, integritas data terpelihara, sesuai dengan tujuan organisasi untuk mencapai efektifitas dan efisiensi dalam penggunaan sumber daya".,"[3]

\subsection{Sistem Informasi Human} Resource Information System Gulati (2012, p. 20) menjelaskan bahwa Human Resource Information System merupakan perangkat lunak yang memiliki database dan memungkinkan untuk melakukan penginputan, penyimpanan dan memanipulasi data dari karyawan yang berada di perusahaan. Ini memungkinkan untuk melakukan visualisasi global dan mengakses informasi penting dari karyawan.[2]

\subsection{COBIT 5}

Menurut ISACA (Information System Audit and Control Asociation) dan ITGI (IT Governance Institute) "COBIT adalah suatu panduan kerja dalam pengelolaan teknologi informasi.". [8]

\subsubsection{Prinsip}

COBIT 5 memiliki Prinsip dan Enabler yang bersifat umum dan bermanfaat untuk semua ukuran perusahaan, baik komersial maupun non-profit ataupun sektor publik. 5 Prinsip tersebut adalah Meeting stakeholder needs, Covering enterprise end-to-end, Applying a single intergrated framework, Enabling a holistic approach dan Separating governance from management.

Berikut

penjelasannya[8]:

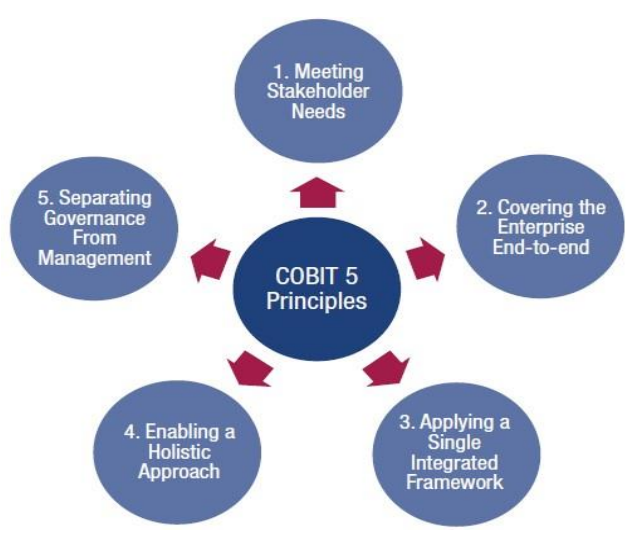

Gambar 2. 1. COBIT 5 Principles (COBIT 5, figure 2. 2012 ISACA)

1. Meeting stakeholder needs, berguna untuk pendefinisan prioritas dalam implementasi, perbaikan, dan jaminan. Kebutuhan stakeholder diterjemahkan ke dalam Goals Cascade menjadi tujuan yang lebih spesifik, dapat ditindaklajuti dan disesuaikan, dalam konteks: Tujuan perusahaan (Enterprise Goal), Tujuan yang terkait IT (IT-related Goal), Tujuan yang akan dicapai enabler (Enabler Goal).

2. Covering enterprise end-to-end, bermanfaat untuk mengintegrasikan tata kelola TI perusahaan kedalam tata kelola perusahaan. Prinsip kedua ini juga meliputi semua fungsi dan proses yang dibutuhkan untuk mengatur dan mengelola TI perusahaan dimanapun informasi diproses.

3. Applying a single intergrated framework, sebagai penyelarasan diri dengan standar dan framework relevan lain, sehingga perusahaan mampu menggunakan COBIT 5 sebagai framework tata kelola umum dan integrator. 
4. Enabling a holistic approach, yakni COBIT 5 memandang bahwa setiap enabler saling memperngaruhi satu sama lain dan menentukan apakah penerapan COBIT 5 akan berhasil, Enabler didorong oleh penjabaran tujuan.

5. Separating governance from management, COBIT membuat perbedaan yang cukup jelas antara tata kelola dan manajemen. Kedua hal tersebut mencakup berbagai kegiatan yang berbeda, memerlukan struktur organisasi yang berbeda, dan melayani untuk tujuan yang berbeda pula.

\subsubsection{Domain COBIT 5}

1. Acquire and Implement (BAI) dengan 10 proses. Domain ini meliputi membangun, memperoleh, dan mengimplementasikan sistem yang mendukung proses bisnis.

2. Deliver, Service and Support (DSS) dengan 6 proses.Meliputi mengirimkan, layanan, dan dukungan atau memberi pelayanan yang aktual bagi bisnis, termasuk manajemen data dan proteksi informasi yang berhubungan dengan proses bisnis.

3. Monitor, Evaluate and Assess (MEA) dengan 3 proses.

Domain ini terdiri dari pengawasan, evaluasi dan penilaian manajemen tentang pengendalian proses-proses, oleh lembaga monitoring independen yang berasal dari dalam dan luar organisasi atau lembaga alternatif lainnya.

\subsubsection{Indikator Kapabilitas Proses dalam COBIT 5}

Menurut ISACA, indikator kapabilitas proses adalah kemampuan proses dalam meraih tingkat kapabilitas yang ditentukan oleh atribut proses. Bukti atas indikator kapabilitas proses akan mendukung penilaian atas pencapaian atribut proses (ISACA, 2012).[8]

Berikut penjelasan Capability Level beserta pencapaian Process Attribute:

1) Level 0 - Incomplete Proces

Pada level ini proses tidak dilaksanakan atau gagal untuk mencapai tujuan prosesnya.

2) Level 1 - Performed Process Pada level ini menentukan apakah suatu proses mencapai tujuannya.

3) Level 2 - Managed Process

Performa proses pada tahap ini dikelola yang mencakup perencanaan, monitor, dan penyesuaian.

4) Level 3 - Established Process Proses implementasi menggunakan proses yang telah didefinisikan untuk mencapai hasil

5) Level 4-Predictable Process Proses operasi dengan batasanbatasan agar mampu meraih harapan dari proses tersebut. Process Attribute 4.1 Process Measurement

6) Level 5-Optimising Process, proses yang terprediksi secara terusmenerus ditingkatkan untuk memenuhi tujuan bisnis saat ini dan tujuan proyek.

\subsubsection{Metode Perhitungan}

Perhitungan Capability Level, Menurut Krisdanto Surendro pada bukunya yang berjudul "Implementasi Tata Kelola TI" (2009). Dijelaskan tentang hasil dari perhitungan kuesioner yang direkapitulasi untuk dapat 
merepresentasikan persentase dan Capability Level. [1]

1) Menghitung Rekapitulasi Jawaban Kuesioner

$$
\frac{\boldsymbol{C}=\boldsymbol{H} \times \mathbf{1 0 0} \%}{\boldsymbol{J} \boldsymbol{R}}
$$

2) Menghitung Nilai dan Level Kapabilitas

3) $\mathrm{NK}=$

$$
\begin{aligned}
& (\text { LPxNka+ }+ \text { LPxNkb) }+(\text { LPxNkc }) \\
& +(\text { LPxNkd })+(\text { LPxNke })+(\text { LPxN } \\
& \text { kf })
\end{aligned}
$$$$
100
$$

\section{Kerangka Penelitian}

Langkah yang akan dilakukan oleh peneliti dalam rangka untuk mengumpulkan informasi dan perencanaan audit SI.

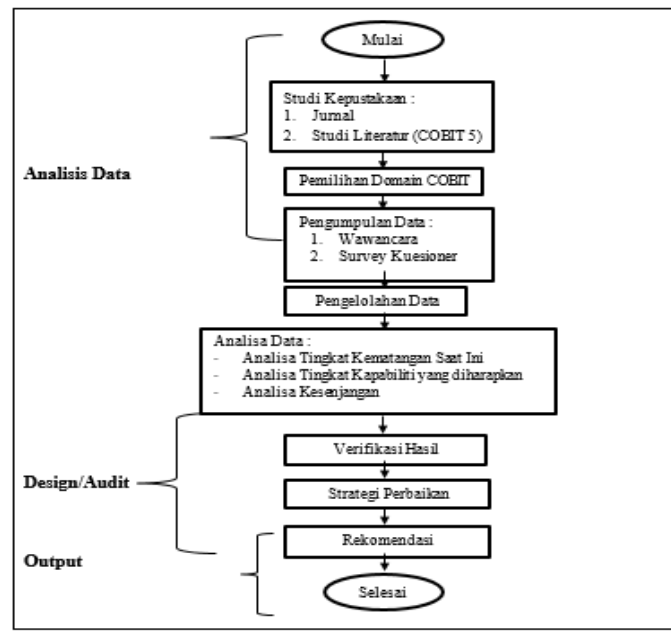

\section{Gambar 3.1}

\section{Gambar Kerangka Penelitian}

\section{Analisis Kesadaran Pengelolaan (Management Awareness)}

Tahapan ini dilakukan berdasarkan hasil dari kuesioner kesadaran pengelolaan mengenai proses manajemen dan sumber daya sistem informasi pada perusahaan, kemudian dilakukan rekapitulasi jawaban agar terlihat mengenai tingkat kepentingan yang menggambarkan tingkat harapan. Selain itu, kuesioner ini juga ditujukan untuk mendeskripsikan mengenai pihakpihak siapa saja yang berkepentingan untuk menjalankan kegiatan yang diharapkan untuk dijalankan.

\subsection{Pemetaan dan Pemilihan Domain COBIT 5}

Domain proses mengacu pada tujuantujuan strategis objek penelitian dalam

\begin{tabular}{|c|c|c|}
\hline $\begin{array}{c}\text { BSC } \\
\text { Dimension }\end{array}$ & $\begin{array}{l}\text { Enterprise } \\
\text { Gooal }\end{array}$ & $\begin{array}{c}\text { Resource } \\
\text { Optimisation }\end{array}$ \\
\hline \multirow{4}{*}{ Financial } & 1. Stakeholder yalue of business investments & $P$ \\
\hline & 2. Portofolio of competitive products and services & $\mathrm{s}$ \\
\hline & $\begin{array}{l}\text { 3. Managed business risk (safeguarding of } \\
\text { assets) }\end{array}$ & $\mathrm{s}$ \\
\hline & 5. Financial Transparencex & $\mathrm{s}$ \\
\hline \multirow{4}{*}{ Customer } & 6. Customers-oxiented serxica. culture & $\mathrm{p}$ \\
\hline & $\begin{array}{l}\text { 8. Agile responses to a changing business } \\
\text { Environment }\end{array}$ & $\mathrm{P}$ \\
\hline & 9. Information-based strategic decision making & $\mathrm{P}$ \\
\hline & 10. Optimisation of serxice deliverx costs & $\mathrm{P}$ \\
\hline \multirow{4}{*}{ Internal } & 11. Optimisation of business process Functionality & $\mathrm{p}$ \\
\hline & 12. Optimisation of business process costs. & $P$ \\
\hline & 13. Managed bussiness change programmes & $\mathrm{s}$ \\
\hline & 14. Operational and staff productivitix & $\mathrm{P}$ \\
\hline $\begin{array}{l}\text { Garning and } \\
\text { Growth }\end{array}$ & 16. Skilled and motivated people & $\mathrm{P}$ \\
\hline
\end{tabular}
hal optimalisasi Sistem Informasi SDM (Sumber Daya Manusia) pada Perusahaan PT. Sansan Saudaratex Jaya.

\section{Gambar 4.1 Enterprise Goals}

\subsection{Mapping Enterprise to IT Related Goals.}

Analisis Enterprise Goals yang telah dilakukan berdasarkan Stake Holder Need yang ada, proses selanjutnya memilih Enterprise Goals (EG) dengan memetakan berdasarkan dimensi balance score card (BSC) dan pemilihan proses diseleksi yang mempunyai tanda Primary di objek tata kelola yaitu resource optimization. proses enterprise goals dengan objek tata kelola terdapat 14 enterprise goals yang terpilih, diantaranya 6 berkategori Primary (P) enterprise goals dan 7 
berkategori Secondary (S) enterprise goals

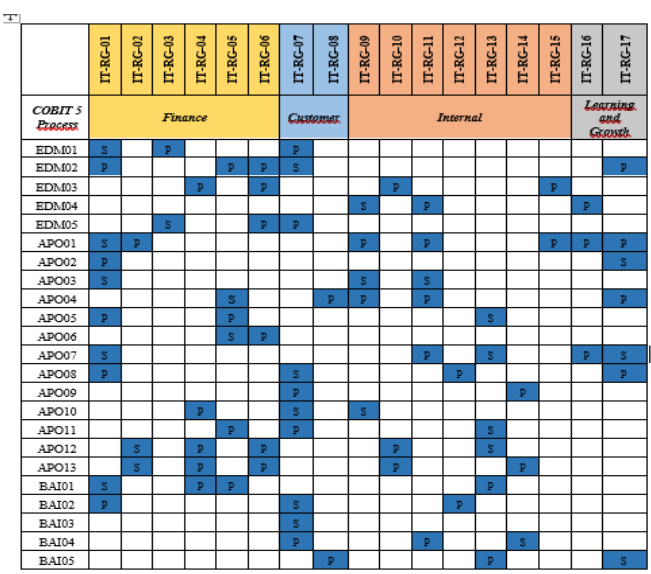

Gambar 4.2

Gambar Mapping Enterprise to IT Related Goals

\subsection{Mapping IT Related Goals To Process}

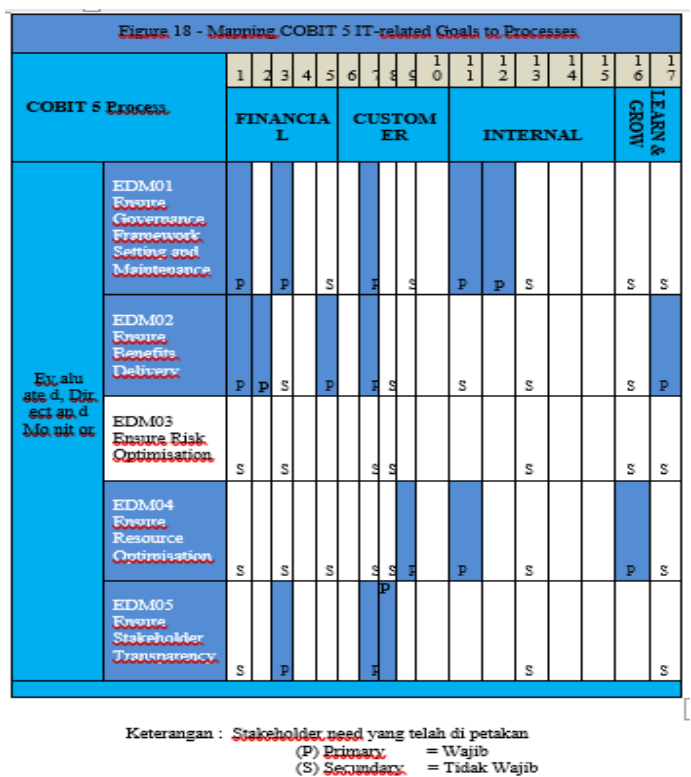

Gambar 4.3

\section{Gambar Mapping IT Related Goals} To Process

\subsection{Analisis Level Kapabilitas (CapabilityLevel)}

Pada tahap ini, dilakukan penentuan tingkat kapabilitas diperusahaan PT.
p-ISSN : 1858-3911, e-ISSN : 2614-5405

https://journal.uniku.ac.id/index.php/ilkom
Sansan Suaadaratex Jaya yang diperoleh dari pengolahan data jawaban responden pada kuesioner capability level menggunakan Skala Rating Scale, menghitung rekapitulasi jawaban responden dan normalisasi responden, menghitung data domain capability level, dan menghitung capability level saat ini (current capability). Objek pertanyaan pada kuesioner capability level dikembangkan dari deskripsi model tingkat kematangan COBIT 5 pada DSS01 yang terdapat pada key management practices. berdasarkan proses capability level yang terdiri dari level 0-5.

\begin{tabular}{|cc|c|l|}
\hline $\begin{array}{c}\text { Rentang } \\
\text { Nilai }\end{array}$ & Jawaban & $\begin{array}{c}\text { Nilai } \\
\text { Kapabilitas }\end{array}$ & \multicolumn{1}{|c|}{ Tingkat Kapabilitas } \\
\cline { 2 - 4 } $0-0,50$ & 0 & 0,00 & 0 (Incomplete Process) \\
\hline $0,51-1,50$ & 1 & 1,00 & 1 (Performed Process) \\
\hline $1,51-2,50$ & 2 & 2,00 & 2 (Managed Process) \\
\hline $2,51-3,50$ & 3 & 3,00 & 3 (Established Process) \\
\hline $3,51-4,50$ & 4 & 4,00 & 4 (Predictable Process) \\
\hline $4,51-5,00$ & 5 & 5,00 & 5 (Optimising Process) \\
\hline
\end{tabular}

Gambar 4.4

Gambar Pemetaan Jawaban Nilai dan Tingkat Kapabilitas 


\subsection{Identifikasi RACI}

Diagram RACI akan dipetakan dengan peran-peran yang terkait pada struktur organisasi PT. Sansan Saudaratex Jaya, sehingga diharapkan jawaban kuesioner sesuai dengan keadaan sesungguhnya di lapangan. Dari pemetaan diagram RACI kedalam struktur organisasi PT. Sansan Saudaratex Jaya didapatkan matriks ternomalisasi.

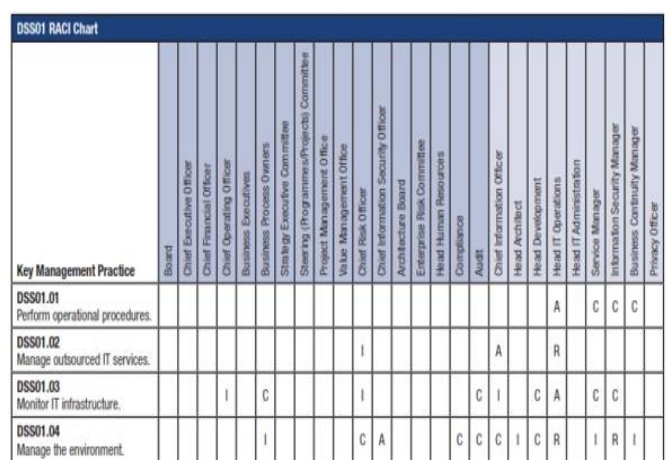

Gambar 4.5

Gambar RACI DSS01 (ISACA, 2012)

\subsection{Analisis Kesenjangan (GAP)}

Analisis Kesenjangan (GAP) Pada tahap ini dilakukan penentuan kesenjangan (gap) antara tingkat kapabilitas saat ini (current capability level) dengan tingkat kapabilitas yang diharapkan (expected capability level). Dengan terdefinisinya gap, organisasi mengetahui seberapa jauh jangkauan yang harus dicapai agar tingkat kapabilitas saat ini mencapai tingkat kapabilitas yang diharapkan, sehingga organisasi dapat menyusun rencanarencana rekomendasi perbaikan yang diperlukan dengan lebih tepat sasaran berdasarkan atribut pada COBIT 5 .

\subsection{Perencanaan Audit}

Setelah dilakukan pengumpulanpengumpulan data, rencana audit yang akan dilakukan pada DSS01 untuk mengetahui apakah fungsi proses bisnis diperusahaan dan mengetahui sejauh mana sebuah sistem informasi HRIS membantu proses bisnis yang diterapkan terhadap sistem yang sesuai dengan prosedur yang ada.

Hasil analisis audit terhadap jawaban kuesioner dari beberapa responden, di gunakan untuk mencari tanggapantanggapan dari para responden mengenai kondisi terkini yang ada pada bagian sistem informasi HRIS terkait dengan domain DSS (Deliver, Service and Support).

\begin{tabular}{|c|c|c|c|c|c|c|c|c|c|c|c|}
\hline DSS01-01 & \multicolumn{6}{|c|}{ KSI } & \multicolumn{5}{|c|}{ KYD } \\
\hline Pertanyaan & 0 & 1 & 2 & 3 & 4 & 5 & 0 & 2 & 3 & 4 & 5 \\
\hline 1. & & & & 50 & & & & & 50 & 25 & 25 \\
\hline 2 & & & 50 & 50 & & & & & 60 & 40 & \\
\hline 3 & & & & 25 & 10 & & & & 33,3 & 75 & \\
\hline 4 & & 10 & 50 & 25 & 15 & & & & 25 & 75 & \\
\hline 5 & 15 & 50 & & 10 & & & & & 15 & 850 & \\
\hline Total & \begin{tabular}{l|l|}
3,8 \\
\end{tabular} & 15 & & 32 & 5 & & & 0 & 36,7 & 21.3 & 2. \\
\hline
\end{tabular}

\section{Gambar 4.7 \\ Gambar Rekapitulasi Kuesioner 1 DSS01-01}

Berdasarkan gambar di atas, maka dapat diketahui, bahwa sistem informasi HRIS menilai kondisi saat ini dalam hal menjalankan prosedur operasional berada pada jawaban 3 dengan kata lain jika jawaban tersebut dipetakan kedalam capability level maka berada di tingkat 2 (Managed Process) dengan persentase $32 \%$. Selain itu, rensponden mengharapkan kondisi yang akan berada pada jawaban 3 atau berada di tingkat kapabilitas 3 (Established Process) dengan persentase 36,7\%. Dan seterusnya di lakukan perhitungan rekapitulasi sampai dengan DSSI-05.

\subsection{Proses Atribut Level}


Pada tahap ini dilakukan kegiatan memberi level pada setiap sub proses, yang bertujuan untuk menunjukkan hasil nilai kapabilitas dan tingkat kapabilitas saat ini dan yang diharapkan . Hasil dari tahap ini adalah sebagai berikut :

Tabel 4.1 Nilai dan Tingkat Kapabilitas

\begin{tabular}{|cll|l|l|}
\hline $\begin{array}{c}\text { Rentang Nilai } \\
0-0,50\end{array}$ & Jawaban & Nilai Kapabilitas & \multicolumn{1}{c|}{ Tingkat Kapabilitas } \\
\hline $0,51-1,50$ & 1 & 0,00 & 0 (Incomplete Process) \\
\hline $1,51-2,50$ & 2 & 1,00 & 1 (Performed Process) \\
\hline $2,51-3,50$ & 3 & 2,00 & 2 (Managed Process) \\
\hline $3,51-4,50$ & 4 & 4,00 & 3 (Established Process) \\
\hline $4,51-5,00$ & 5 & 5,00 & 4 (Predictable Process) \\
\hline
\end{tabular}

Berikut ini adalah hasil nilai kapabilitas proses DSS01 (Manage Operational), yang didapat dengan menggunakan rumus penilaian yang dijelaskan sebelumnya. Dari hasil penilaian kuesioner didapatkan dari hasil perhitungan pencapaian capability yang dapat dilihat rincian perhitungannya pada penjelasan process capability pemetaan jawaban Nilai dan Tingkat Kapabilitas.

Berdasarkan perhitungan tersebut, dapat diketahui bahwa kondisi saat ini berada pada tingkat kapabilitas 2 (Manage Process), dengan nilai kapabilitas sebesar 2.27, yang artinya proses melakukan prosedur operasional sudah dilakukan pengaturan berupa perencanaan, monitor, dan penyesuaian. Selain itu, kondisi yang diharapkan berada pada tingkat kapabilitas 3 (Established Process) dengan nilai kapabilitas sebesar 3.33, yang artinya proses melakukan prosedur operasional diharapkan dapat diimplementasikan dengan menggunakan proses yang telah didefinisikan. Begitupun seterusnya perhitungan nilai kapabilitas di lakukan sampai dengan DSS01-05.

Langkah berikutnya adalah menghitung level Kapabilitas , dan hasilnya sebagai berikut :

\section{Tabel 4.2 Rekapitulasi Capability}

\begin{tabular}{|c|c|c|c|c|c|}
\hline \multirow{2}{*}{ No } & \multirow{2}{*}{ Aktivitas } & \multicolumn{2}{c|}{ Nilai Kapabilitas } & \multicolumn{2}{c|}{ Tingkat Kapabilitas } \\
\cline { 3 - 6 } & Kondisi & $\begin{array}{c}\text { Kondisi } \\
\text { yang } \\
\text { sani }\end{array}$ & $\begin{array}{c}\text { Kondisi } \\
\text { saat ini }\end{array}$ & $\begin{array}{c}\text { Kondisi } \\
\text { yang } \\
\text { diharapkan }\end{array}$ \\
\hline 1 & DSS01.01 & 1.36 & 3.8 & 2 & 3 \\
\hline 2 & DSS01.02 & 2.87 & 4.1 & 3 & 4 \\
\hline 3 & DSS01.03 & 1.8 & 2.54 & 1 & 3 \\
\hline 4 & DSS01.04 & 2.05 & 3.6 & 2 & 3 \\
\hline 5 & DSS01.05 & 2.9 & 4 & 2 & 3 \\
\hline \multicolumn{2}{|c|}{ Rata - Rata } & $\mathbf{2 . 1}$ & $\mathbf{3 . 6}$ & $\mathbf{2 . 0 0}$ & $\mathbf{3 . 2}$ \\
\hline
\end{tabular}

\subsection{Pencapaian Proses Sistem Informasi HRIS}

Berdasarkan hasil perhitungan dari tahapan sebelumnya, maka diketahui hasil tingkat kapabilitas saat ini (Manage Process). Berdasarkan pencapaian pada PA 1.1 Process performance Penentuan level 1 ditiap aktivitas dilakukan dengan melakukan rata-rata base practice dan work product output dari 20 responden, untuk perhitungan dapat dilihat pada lampiran perhitungan pencapaian. Pada form assessment untuk level 1 memperoleh pencapaian nilai capability $86 \%$ yaitu full achieved yang berarti ada bukti pada proses yang dinilai dan pencapaian penuh, karena penilaian full achieved berada pada pencapaian $>85 \%$ - 100. Oleh karena itu dapat melanjutkan level selanjutnya.

Dan dilakukan analisi seterusnya pada kegiatan-kegiatan operasional lainnya. Selanjutnya di buat tabel kesenjangan (GAP). 


\section{Kesimpulan dan Saran 5.1.Kesimpulan}

Berdasarkan hasil analisis yang telah diuraikan pada pembahasan sebelumnya, berikut adalah simpulan yang dapat peneliti berikan dalam bab ini.

1. Nilai kapabilitas Bidang Infrastruktur Informasi pada proses DSS01 (manage operational) saat ini berada di level 2 (managed process) dengan nilai kapabilitas sebesar 2.1. Sementara, tingkat kapabilitas yang diharapkan berada di level 3 (established process) memiliki nilai kapabilitas 3.6. Diantara rentang nilai pada level 2 dan level 3 terdapat nilai gap 1,5. Artinya, untuk mencapai level yang diharapkan tersebut, bagian pengelolan Sistem Informasi Informasi Human Resource Information System (HRIS) pada bagian HR harus dapat memenuhi indicator kapabilitas proses Work Products pada level 1 yang masih belum terpenuhi. Diantaranya seperti membuat laporan kebijakan asuransi, laporan penilaian fasilitas, dan diharuskan membuat jadwal opersional sesuai prosedur agar dapat dimonitoring dengan baik dan pemeliharaan sistem dan jaringan infrastruktur secara rutin dan konsisten, yang didukung dengan standard operating prosedur dalam mendukung kegiatanya. Setelah itu, untuk dapat melanjutkan pada level 2 bagian pengelolaan Sistem Informasi HRIS harus melaksanakan hal yang sama untuk dapat naik ke level selanjutnya.

2. Berdasarkan kesimpulan dari parameter penilaian Sistem Informasi HRIS pada bagian SDM di PT. Sansan Saudaratex Jaya bahwa SI berjalan dan mendukung proses bisnis namun masih banyak kekurangan hal ini dikarenakan dapat di lihat di tabel BSC dan Kesenjangan

\subsection{Saran}

Berdasarkan simpulan yang dijelaskan di atas, pada bab ini peneliti memberikan saran yang dapat menjadi pertimbangan maupun untuk bahan evaluasi bagi pengelolaan Sistem Informasi Informasi Human Resource Information System (HRIS ) pada bagian HR yaitu :

1. Bagian pengelolaan Sistem Informasi Informasi Human Resource Information System (HRIS) disarankan untuk lebih serius memperhatikan dalam mengelola masalah, membuat jadwal operasioanal

2. Dianjurkan untuk membuat dokumentasi setelah melaksanakan kegiatan yang berhubungan dengan layanan dan dokumentasi itu sangat berguna sebagai bahan evaluasi dimasa yang akan datang.

3. Perusahaan diharapkan dapat menginplementasikan semua rekomendasi Proses DSS01 yang terdapat pada tabel IV.19

4. Bagi peneliti selanjutnya yang melakukan evaluasi tata kelola teknologi informasi khususnya pada Sistem Informasi Informasi Human Resource Information System (HRIS) dapat memilih domain proses yang berbeda dalam COBIT 5 atau menggunakan framework lain seperti ITIL dan menggunakan skala yang berbeda seperti Guttman.

\section{Daftar Pustaka}

[1\} Adriana, D. (2016). PENGUKURAN KINERJA Pelayanan 
JURNAL NUANSA INFORMATIKA

Volume 15 Nomor 2, Juli 2021
p-ISSN : 1858-3911, e-ISSN : 2614-5405

https://journal.uniku.ac.id/index.php/ilkom

Disamsat Kota Semarang 1 Menggunakan Cobit 5 Dan Metode Persepsi Kualitas.

[2] Anza, F. A., Sensuse, D. I., \& Ramadhan, A. (2017). Developing EGovernment Maturity Framework Based on COBIT 5 and Implementing in City Level: Case Study Depok City and South Tangerang City. Proc. EECSI, 19-21.

[3] Achyar Al-Rasyid (2015). Analisis Audit Sistem Informasi Berbasis COBIT 5 Pada Domain Deliver, Service, and Support (DSS). (Studi Kasus: SIM-BL di Unit CDC PT Telkom Pusat. Tbk).

[4] Ramdhany, Tri., Kurniasih, S.Perencanaan Strategi Sistem Informasi Retail Studi Kasus: PT Retail X. Bandung: PKN LPKIA.

[5] Hidayat, R. M. (2016). Usulan Tata Kelola Teknologi Informasi Berdasarkan COBIT 5 Pada PT Bumi Technology Pratama (Fokus APO10, BAI04, dan DSS03). Jakarta: UIN Syarif Hidayatullah.

[6] Indrajit, R. (2014). Manajemen Organisasi dan Tata Kelola Teknologi Informasi.

[7] Yogyakarta: Graha Ilmu.

[8] ISACA. (2012). Governance 